\title{
Research on the Construction of Financial Technology Risk Prevention and Control System
}

\author{
Qi Mingchun
}

\begin{abstract}
School of Digital Economics, Sichuan Vocational and Technical College, Suining, Sichuan, China 18835526@qq.com
\end{abstract}

\begin{abstract}
The development of financial technology has changed the financial format and reshaped the financial pattern, at the same time, it also brings a series of risks of traditional finance and technology finance, the importance and urgency of financial technology risk monitoring, early warning and prevention and control is particularly prominent and important. In order to guide and promote the sound operation of financial technology in "integrity, safety, inclusive and open", it is necessary to comprehensively and deeply analyze the types and causes of financial technology risks, building a comprehensive and effective financial risk prevention and control system under the co governance of the whole society.
\end{abstract}

Keywords: Financial Technology, Financial Innovation, Traditional Financial Risk, Technological Financial Risk, Risk Prevention and Control

\section{金融科技风险防控体系构建研究}

\author{
漆明春
}

四川职业技术学院数字经济学院，遂宁，四川，中国

18835526@qq.com

\section{摘要}

金融科技的发展改变了金融业态、重塑了金融格局，同时也带来了一系列传统金融与科技金融风险问题，金融 科技风险的监测、预警及防控的重要性与紧迫性显得尤为突出和重要。为了引导和推动金融科技 “守正、安全、 普惠、开放” 地稳健运行，有必要全面深入分析金融科技风险种类及成因，构建全社会共治的全面有效金融风 险防控体系。

关键词: 金融科技，金融创新，传统金融风险，

\section{1. 引言}

近几年，中国金融科技快速迭代发展和应用，有力 地推动了金融业转型升级, 赋能了金融发展提质增效, 深化了金融供给侧结构性改革，助力了金融风险技防水 平，提升了金融服务实体经济能力（见表 1 ）。然而， 金融科技的发展是把双刃剑，金融科技的快速发展和应 用也会带来诸如加大金融风险的复杂性，放大金融风险 的传染性，扩大金融风险的波及面，增大金融风险的管 控难度等诸多挑战。故而在享受金融科技效益的同时也 有必要关注其所带来的风险, 金融科技风险的监测、预 警及防控的重要性与紧迫性显得更加尤为突出和重要 （见图 1）。2019 年 9 月，中国人民银行印发的《金融 科技发展规划 (2019-2021 年) 》指出要正确把握金融科
科技金融风险，风险防控

技创新与安全的关系，明确新技术应用的运行监控和风 险应急处置策略，做好新技术自身风险和应用风险防 范。2021 年 1 月，在北京召开的人民银行金融科技委员 会会议强调推动建设国家金融科技风险监控中心，构建 风险联防联控体系。

表 1 2013-2019 年中国金融科技营收规模及增长情 况（资料来源：前瞻研究院）

\begin{tabular}{|c|c|c|}
\hline 年份 & 营收规模 (亿元) & 营收规模增长率 $(\%)$ \\
\hline 2013 & 695.1 & - \\
\hline 2014 & 1407.4 & 102.47 \\
\hline 2015 & 2967.1 & 110.82 \\
\hline 2016 & 4213.8 & 42.02 \\
\hline
\end{tabular}




\begin{tabular}{|c|c|c|}
\hline 2017 & 6541.4 & 55.24 \\
\hline 2018 & 9668.8 & 47.81 \\
\hline 2019 & 14365 & 48.57 \\
\hline
\end{tabular}

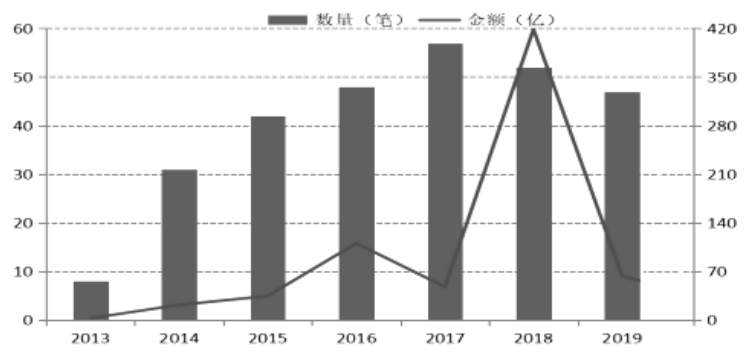

图 1 2013-2020 年中国金融科技风控服务商融资情 况 (资料来源: 零壹智库)

\section{2. 金融科技风险种类及成因分析}

金融科技是人工智能、大数据、云计算、物联网等 新技术驱动的金融创新, 是信息技术与金融深度融合的 产物。相比传统金融而言, 金融科技更加侧重于新技术 的应用, 但是其本质属性仍然是金融, 传统金融风险属 性和类型并未发生实质性的变化, 金融科技仍然具有传 统金融风险, 只是因为技术的应用使风险变得更加复杂 和更加具有隐蔽性。与此同时，金融科技的运用产生了 新的科技金融风险, 甚至有可能因为新技术的技术属性 致使金融风险增加、集聚、叠加而引发系统性金融风险。

\section{1 传统金融风险}

\section{1. 1. 信用风险}

虽然金融科技在很大程度上缓解了信息不对称性 问题，但是信息披露缺陷、市场主体违约等因素导致的 逆向选择和道德风险仍在存在, 信用风险仍然是金融科 技所面临的最普遍、最基础的风险。从金融市场层面来 看, 社会整体信用环境不够良好、信息披露制度不完善、 社会信用体系不健全、交易主体间安全保障制度还不完 备等问题会导致信用风险。从金融机构层面来看, 数据 录入不完整、数据及时更新能力不足、数据质量不高等 因素导致出现信用风险的可能性变大。从个人层面来 看, 收入水平、消费习惯、个人素养、知识结构、能力 水平等都有可能导致不能按时还款甚至无法还款的情 形, 从而诱发信用风险。尤其是当部分人群违约但是没 有付出代价或者代价较低时, 易受从众思想影响而导致 大规模的信用危机发生; 或者当经济形势不景气或者发 生金融危机时, 居民收入水平的持续下滑也会导致大规 模信用危机的发生。

\section{1. 2. 流动性风险}

一方面，金融科技的应用和发展加快了信息传递速 度、增加了产品使用及交付频率, 提升了市场反馈速度, 缩短了产品兄付时效, 客观上增加了金融科技流动性风 险发生概率。另一方面, 金融科技市场投资者知识水平
参差不齐、能力水平高低不同、眼界和思维局限性差异 会导致出现非理性投资现象。金融科技服务商重流量、 追效益、轻风控的经营理念、受监管程度较低等因素会 刺激金融科技服务商采取承诺高利率、违规拆标、集中 兄付等手段实现短期目标和光鲜账面，如果一旦发生社 会金融危机、行业不经济、市场波动、企业价值增长乏 力、产品资金期限错配等情况，金融科技服务商的资金 链条有可能断裂，这就会导致流动性风险的发生。同时， 一旦发生流动性风险，金融科技服务商更加有可能发生 隐瞒实际状况、虚假宣传、拆东墙补西墙等不自律行为, 这必然会集聚、恶化流动性风险, 导致引发群体性的大 规模资金挤兄现象，引起社会动荡与不安。

\section{1. 3. 操作风险}

金融科技操作风险主要原因是操作失误和系统缺 陷。操作失误层面：一方面，由于金融科技业务专业性 较强, 部分客户金融科技相关知识较欠缺，对金融科技 交易业务和产品的了解程度不够, 操作能力和水平不强 等容易导致其操作超过其风险承受能力的业务，这会导 致操作风险的发生。另一方面, 由于金融科技服务商内 部组织结构不合理、规章制度不完善、控制体系不健全、 管理制度不规范, 制度执行不到位、安全意识淡薄、操 作经验不足等因素都容易导致发生指令出现差错等操 作失误现象，一旦风险发生时不能及时有效纠正和处 置, 所造成的后果往往是严重性的。系统缺陷层面: 金 融科技服务商软硬件信息技术基础设施不完善、系统漏 洞、设备故障等系统缺陷和外部网络病毒攻击等都有可 能导致客户信息泄露, 给企业和客户带来直接或者间接 损失，引发操作性风险。

\section{1. 4. 法律风险}

首先，随着金融科技的快速发展和应用，金融科技 创新立法滞后现象较为突出, 创新发展与合规监管之间 的矛盾调和难度加大，现有法律制度将难以对新型金融 交易模式、金融业态状况、金融业务流程、金融产品范 围、金融操作行为做到提前监管, 由此引发法律风险。 其次，传统金融违法犯罪行为在技术外衣包装下更加让 人防不胜防。逾越法律红线、违规操作、套取账户资金、 骗取资本金等违反法律法规或不符合法律法规的事件 时有发生, 给企业、客户乃至整个社会带来巨大损失。 最后，金融科技服务商可能因为信息不对称原因对合作 机构资质审核失误，进而选择了不合格的机构进行合 作，所开展的合作业务存在违法违规现象，导致合规风 险的发生。金融机构服务商在数据收集、存储、使用程 序上不符合法规要求, 数据收集、存储成本过高, 数据 质量较低, 数据可使用率较低, 导致数据合规风险。

\section{2. 科技金融风险}

\section{2. 1. 技术安全风险}

首先，金融科技的发展使金融服务出现数字化、网 络化、智能化、开放化、虚拟化特征，大大增加了金融 对信息技术的依赖程度。一旦系统出现技术漏洞，受到 网络攻击都有可能导致隐私被侵犯、数据被篡改、信息 
泄露或丢失等技术风险的发生, 给客户和金融科技服务 商造成严重的经济损失。而且科技发展越快, 技术风险 严峻性越重, 发生技术风险的概率和造成的破坏损失越 大。其次, 金融科技属于高新技术领域, 金融科技服务 商一般都希望早日布局以占领技术制高点, 往往在金融 科技发展初期就进行布局和参与。金融科技尚处于发展 初期, 受技术成熟度不够影响, 金融科技服务商面临较 高的技术不成熟、技术失控、算法不完善、系统设计不 合理、数据存储传输安全性不高等技术缺陷, 如果此时 为了盲目追求技术进步而忽视技术试用与检验, 就会产 生企业无法预测与不可控制的技术风险，进而造成无法 修复和挽回的损失, 甚至有可能对整个经济社会产生较 为严重的负面影响。

\subsection{2. 业务安全风险}

金融科技服务商往往采用提高用户技术体验感、创 新金融产品品种、创新技术服务方式等手段来增加产品 销售量以扩大效益。首先，金融科技服务商往往为了所 谓的技术效益，忽视了金融交易中一些必不可少的审查 环节, 未能找准金融业务所服务的对象范围, 使不具备 条件或者非优质客户享受了金融科技服务的便利, 金融 业务刚开始就从源头上蕴含了较高风险。其次, 金融科 技服务商在创新金融产品时, 由于盲目相信技术创新, 所创新的金融产品不能适用客户需求或者不能根据客 户的风险承受能力出售合适金融产品，使金融业务针对 性不强, 导致金融产品安全风险。最后, 金融科技的发 展会导致金融业务日益壮大、业务内容逐渐增加, 这使 得网络系统中累积海量的需要处理与保护的金融业务 与产品数据。但当前的信息管理系统防御性能还不完 善, 还不能完全应对虚拟环境下频繁的网络攻击, 造成 业务和产品数据被盗取、被篡改，导致客户和自身遭受 严重损失的可能性增大, 甚至可能破坏整个外部金融环 境。

\section{3. 构建金融科技风险防控体系之策}

金融科技提高了金融市场运行效率，催生了金融业 新业态、新模式, 改变了金融支付形式、服务方式, 促 进了社会进步和经济发展。同时, 我们也要意识到, “水 能载舟, 亦能覆舟”, 金融科技也带来了一系列风险, 如果金融科技应用不当, 种种风险叠加在一起爆发, “蝴 蝶效应” 也会对金融业造成更大的冲击，给金融领域掀 起一场轩然大波, 危害金融业稳定, 扰乱社会交易秩序, 影响国民经济健康可持续稳定发展。所以，在金融科技 浪潮下, 我们需要保持一份冷静与定力, 要及时观察、 发现、捕捉金融科技发展中出现的不稳定因素，在发挥 科技创新优势的同时构建政府部门、金融科技服务商、 行业协会、社会各界共同构成的全面有效共治金融科技 风险防控体系, 以保证金融科技稳健运行。

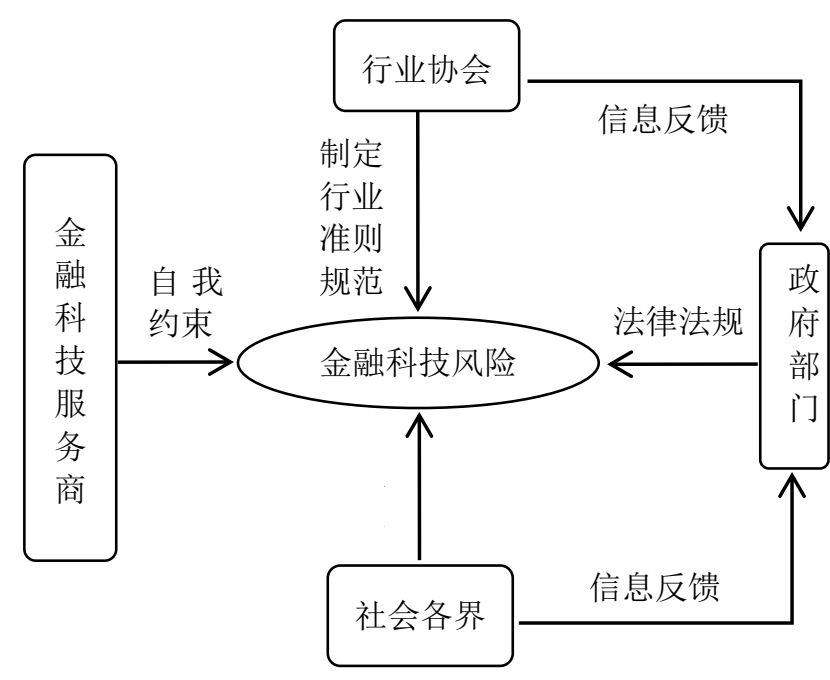

图 2 金融科技风险共治防控体系框架

\section{1. 金融科技服务商自我约束}

金融科技服务商处于金融科技创新与应用第一线， 通常情况下比社会其他组织更加了解金融科技技术，明 晰金融科技发展趋势，明确自我业务方向，熟悉自身金 融产品，金融科技参与主体的自我约束能够充分发挥自 身的专长，有效减少金融科技风险发生概率，能够构筑 起第一道金融科技风险防控线。首先，金融科技服务商 通常更加了解金融科技内涵、发展现状及趋势，更加关 注竞争对手的新动向, 在创新金融科技时有利于扬长避 短，加强服务商之间的互相约束和监督。其次，金融科 技服务商创新了金融科技业务与产品，在运行机制、运 作模式等特定信息的掌握上和风险点的识别上比其他 任何社会组织都具有优势, 更能有效地约束自我行为。 例如，金融科技服务商更加了解虚拟货币平台的货币运 行机制及风险点; 更加了解智能机器人的投资算法及风 险点; 更加了解众筹网站的运作模式及风险点。

\section{2. 政府部门监管}

市场主体的最终目的是追求自身效益，政府部门必 须保持政府监管的核心地位，以实现金融科技发展的社 会效益。在金融科技发展中，政府部门要同时兼顾金融 科技创新与风险防控，实现创新与风险之间的平衡。第 一、政府部门要进行监管创新。政府部门要与时俱进构 建联合监管组织、调整监管方式、转变监管理念，变传 统的看守式、被动式监管为主动式、穿透式监管，通过 顶层设计明确监管主体、完善监管制度，保障金融科技 稳健运行。一方面，有必要由国务院金融稳定发展委员 会牵头，人民银行、银保监会、证监会等相关部门根据 现有金融科技创新发展态势及金融监管体系，构建符合 我国国情的联合监管组织，通过跨部门的统筹协调预防 监管套利和监管真空, 筑牢坚实组织保障。另一方面, 政府部门要积极开展当前国际流行的 “监管沙盒” 先行 先试, 在试点基础上逐渐扩大申请主体与业务范围, 要 将创新主体、实际业务、具体产品串联起来进行全过程 监管。第二、健全金融科技法律体系。随着金融科技的 发展, 政府部门出台了一系列相关保障金融科技健康发 展的规章制度。但是, 伴随金融科技创新的深入推进, 
新风险、新矛盾、新问题层出不出, 有必要加快完善金 融科技审批、备案、准入、交易、认证、退出、监管等 方面更加有针对性和适应性的法律制度，保护市场主体 利益的同时满足金融科技发展的需要, 为金融科技健康 运行提供有效的法律保障机制。

\section{3. 行业协会自律}

行业协会具有贴近金融市场与协会会员的天然优 势，具有自律行业行为、信息披露、线索举报的职能， 有必要将行业协会作为构建金融科技风险防控体系的 重要补充, 降低监管部门和市场间的沟通成本。为推动 金融科技创新发展, 我国可借鉴英国金融行为监管局以 及新加坡金融管理局等外国监管部门的经验做法, 整合 中国互联网金融协会、中国证券业协会、各类金融交易 所等行业组织, 组建专门的金融科技监管协会, 充分发 挥行业协会的服务、协调、监督作用。同时, 全面开展 行业信息披露、行业准则制定、从业人员行为规范、投 资者权益保护等监测统计工作, 引导相关市场主体进行 审慎经营, 规范市场从业人员行为, 明确工作人员岗位 职责, 增强市场主体责任意识, 提高投资者的风险防范 意识, 推动金融科技行业稳定发展。

\section{4. 社会各界监督}

在信息技术迅猛发展的当下，信息资源的价值更加 明显, 政府部门和金融服务商之间也存在信息不对称现 象。首先, 政府部门有必要疏通社会各界监督与举报信 息渠道, 畅通信息反馈及沟通渠道, 通过提高信息的可 获得性辅助决策施政。其次, 政府部门要将中介机构、 社会公众等纳入到金融科技风险共治防控体系，完善有 奖举报等正向激励机制, 提高参与主体进行自我监管和 外部监督的积极性, 鼓励和引导社会各界积极参与金融 科技风险防控。最后，要开展投资者金融科技基础知识、 金融科技风险及防范等方面的教育, 全面提升社会各界 的金融素养与监督意识, 推动市场参与者主动加强自律 行为, 引导形成良好的 “理财有风险, 投资需谨慎” 的 理性投资社会氛围, 以此降低金融科技领域的系统性风 险。

\section{4. 结论}

金融科技的发展是创新与风险并存的，从传统和科 技角度全面深入分析金融科技风险, 采用系统论理念来
构建全社会共治的全面有效金融风险防控体系，金融科 技风险将会得到有效防范，金融科技的发展将会变得更 有规则，对引导和推动金融科技 “守正、安全、普惠、 开放” 地稳健运行具有重要的现实意义。也更加有利于 保护市场主体利益, 更加有利于造福国家社会各成员, 更加有利于服务实体经济发展。

\section{项目基金}

本文为四川省教育厅项目《四川 “插花式” 贫困地 区创新金融精准扶贫机制研究》（18SB0696）的阶段性 研究成果之一。

\section{作者简介}

漆明春（1981-），男，汉族，四川遂宁人，金融 学硕士, 四川职业技术学院副教授。主要研究方向：金 融与区域经济。

\section{REFERENCES}

[1] Liu, M.F. (2020)Potential Risks of Financial Technology and Regulatory Response. J. Southern Finance., 06: 45-55.

[2] Chen, H., Y, C. (2019)Research on Financial Technology Risks and Countermeasures. J. Shanghai Enterprises., 03: 67-71.

[3] He, X.M. (2019)Research on Financial Technology Risks and Countermeasures. J. Mall Modernization., 11: 99-100.

[4] Zhang, K. (2021)Financial Technology: Risk Derivation, Regulatory Challenges and Governance Path. J. Southwest Finance., 03: 39-51.

[5] Cui, B.R. (2019)Risk Analysis and Suggestions of Financial Technology. J. Modern Communication., 12: $72-74$.

[6] Q, W., Gao, J. (2019)On the Causes and Prevention of Financial Technology Risks. J. Northern Finance., 09: 68-71. 